$\mathrm{H}$ евоидная гипопигментация как проявление мозаицизма кожи

\author{
Д.В. Прошутинская, Л.В. Текучева
}

ФГБУ «Государственный научный центр дерматовенерологии и косметологии» Минздрава России 107076, Москва, ул. Короленко, д. 3, стр. 6

Представлено описание клинического случая редкой генетически обусловленной дисхромии - невоидной гипопигментации. Заболевание рассматривается как проявление кожного мозаицизма с характерными особенностями клинической картины. Приводятся данные литературы, обсуждаются вопросы дифференциальной диагностики данной патологии.

Ключевые слова: дисхромия, невоидная гипопигментация, мозаицизм.

Контактная информация: diana.dika@mail.ru. Вестник дерматологии и венерологии 2015; (5): 86-90.

\title{
Nevoid hypopigmentation as a manifestation of skin mosaicism
}

\section{D.V. Proshutinskaya, L.V. Tekucheva}

State Research Center of Dermatovenereology and Cosmetology, Ministry of Healthcare of the Russian Federation Korolenko str., 3, bldg 6, Moscow, 107076, Russia

A case report of rare genetically specified dyschromia - nevoid hypopimentation - was described. This disease is considered as a manifestation of skin mosaicism with characteristics of clinical presentation. Literature data is given, differential diagnostics issues of this pathology are discussed.

Key words: dyschromia, nevoid hypopigmentation, mosaicism.

Corresponding author: diana.dika@mail.ru. Vestnik Dermatologii i Venerologii 2015; 5: 86_90. 
Дисхромии, или нарушения пигментации кожи, составляют разнообразную по своим клиническим проявлениям группу дерматозов. Ведущая роль в формировании цвета кожи отводится пигменту меланину, синтезируемому в клетках базального слоя эпидермиса - меланоцитах. Нарушение меланогенеза под влиянием различных экзогенных и эндогенных факторов может приводить к усилению пигментации кожи гиперпигментации или к уменьшению - гипопигментации. По данным исследователей, гипопигментации наблюдаются менее чем у $1 \%$ новорожденных [1], являясь достаточно редкой патологией кожи. В то же время это может быть связано с поздним выявлением заболевания из-за определенных трудностей диагностики. Очаги гипопигментации плохо визуализируются на коже новорожденного, отличающейся выраженным светлым оттенком цвета. Со временем, по мере фрормирования нормальной пигментации, гипопигментированные пятна становятся более отчетливо видимыми, вызывая тем самым беспокойство родителей.

В зависимости от распространенности и очертаний очагов в литературе принято выделять несколько ти- пов врожденных гипопигментаций: локализованные, генерализованные и мозаичные. Последние представляют собой наибольший клинический интерес своей редкостью и возможностью сочетания с патологией других органов и систем.

Под термином «мозаицизм» подразумевается состояние, при котором вследствие хромосомных мутаций или аберраций не все клетки организма содержат одинаковый набор хромосом. В результате в одном организме могут присутствовать две или более генетически различные клеточные популяции [2]. Кожный мозаицизм проявляется своеобразным расположением и рисунком дисхромических очагов. В зависимости от расположения очагов гипопигментации выделяют следующие варианты мозаичных гипопигментаций: узкие линии Блашко, широкие линии Блашко, по типу шахматной доски, фриллоидный (листообразный), пятнистый без срединной линии, латеральный (рис. 1).

Целью нашего сообщения является описание клинического случая мозаичной гипопигментации с сочетанием нескольких вариантов расположения дисхромических очагов.
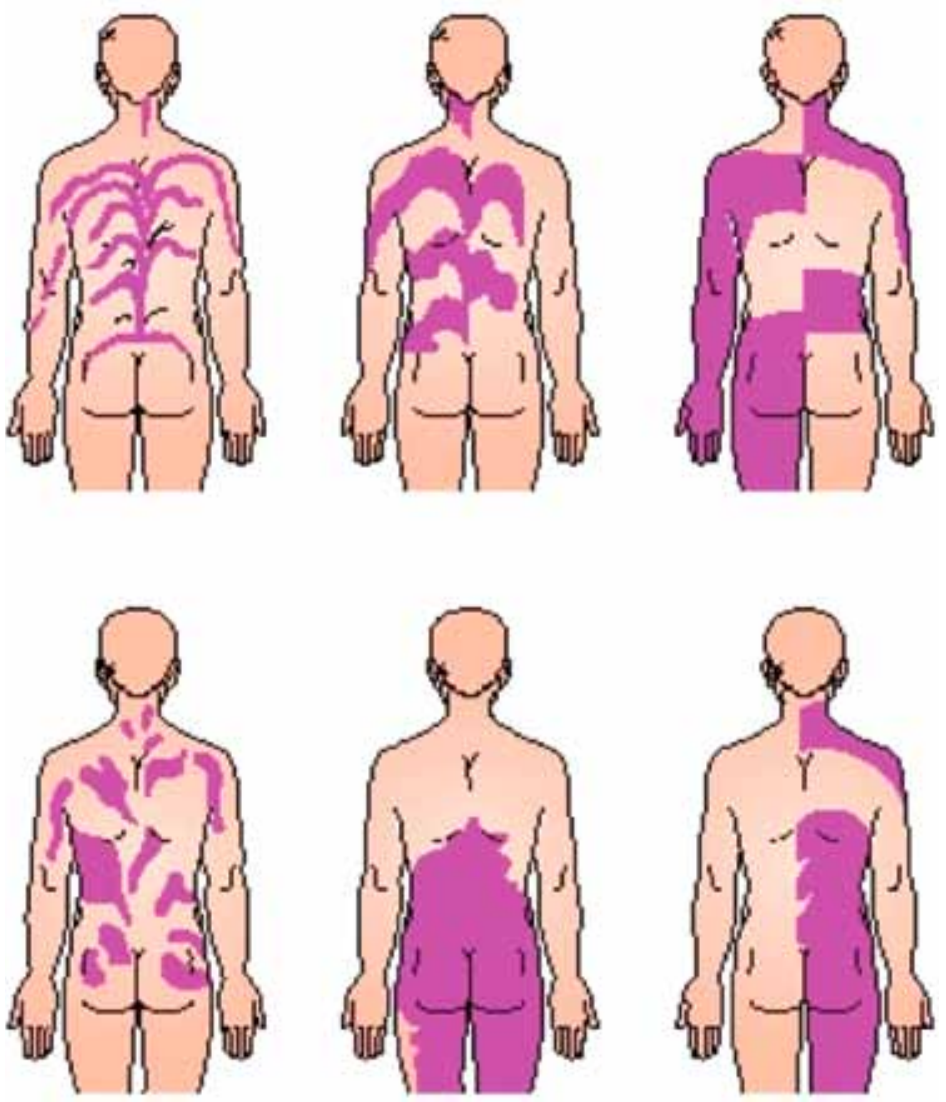

Рис. 1. Варианты мозаичной гипопигментации: узкие линии Блашко, широкие линии Блашко, по типу шахматной доски, фриллоидный (листообразный), пятнистый без срединной линии, латеральный [3] 


\section{Клинический случай}

Девочка 1,5 года, родители которой обратились с жалобами на наличие у ребенка пятен белого цвета на коже лица и шеи, в области груди, живота, спины, преимущественно слева, левых верхней и нижней конечностей. An. morbi: в возрасте 2 мес. родители заметили на коже ребенка гипопигментированные пятна, в связи с чем обратились к детскому дерматологу в поликлинику по месту жительства. На основании клинической картины высыпаний были установлены предварительные диагнозы: пьебалдизм, синдром Ваарденбурга, синдром Блоха - Сульцбергера. Со слов родителей, со временем отмечается увеличение очагов в размерах пропорционально росту ребенка. С целью уточнения диагноза обратились на прием к детскому дерматологу в ФГБУ «ГНДЦК» Минздрава России.

An. vitae: ребенок из двойни, от первой беременности, протекавшей с угрозой прерывания, первых преждевременных родов. Ребенок с рождения находился на искусственном вскармливании. Прикормы вводились по рекомендации педиатра. До возраста одного года наблюдалась невропатологом по поводу выраженной незрелости головного мозга, дисплазии тазобедренных суставов. В настоящее время состоит на диспансерном учете у невропатолога. В возрасте 1 года 2 мес. проведено хирургическое иссечение множественных гемангиом. Аллергологический и наследственный анамнезы не отягощены.

St. localis: при осмотре ребенка кожный патологический процесс носит распространенный выраженный асимметричный характер с поражением преимущественно левой половины лица, туловища и конечностей. На лице в области лба слева, на щеке и подбородке также слева депигментированные пятна с четкими границами. На переднебоковой поверхности туловища визуализируются гипопигментированные пятна волнистых очертаний и очаги гипопигментации S-образной формы по типу широких линий Блашко (рис. 2). На спине высыпания представлены гипопигментированными V-образными или фонтаноподобными пятнами по типу узких линий Блашко (рис. 3). На левой верхней и нижней конечностях имеются линейные очаги депигментации с островками нормально пигментированной кожи, отдельные гиперпигментированные пятна округлых очертаний от 3 мм до $1 \mathrm{~cm}$ в диаметре (рис. 4).

При лабораторном обследовании общие клинические анализы крови и мочи, биохимический анализ крови - без патологии. Ребенку проведены консультации кардиолога, офтальмолога, эндокринолога, хирурга, онколога, ортопеда. По результатам обследования выявлены обменные изменения в миокарде, анизокория II степени, увеличение щитовидной железы 0-I степени, укорочение левой нижней конечности, меланоцитарные невусы.

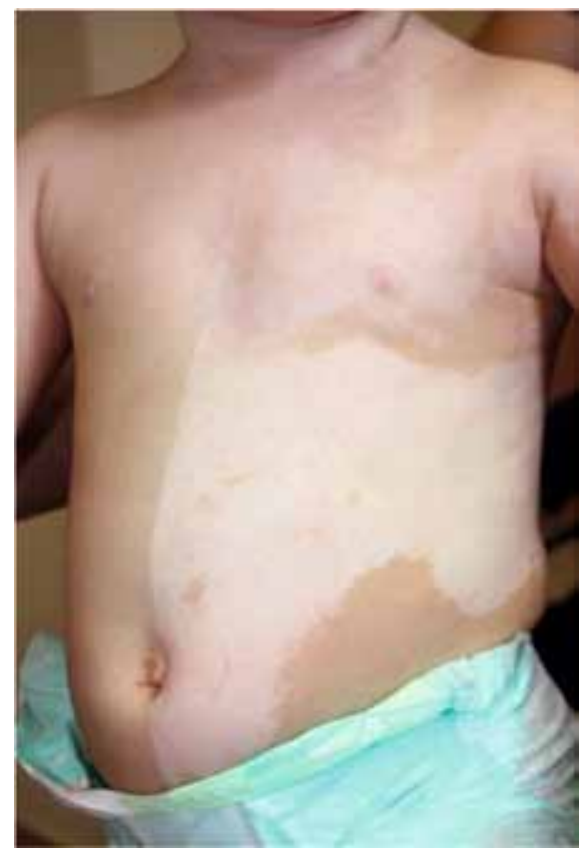

Рис. 2. Очаги гипопигментации S-образной формы по типу широких линий Блашко

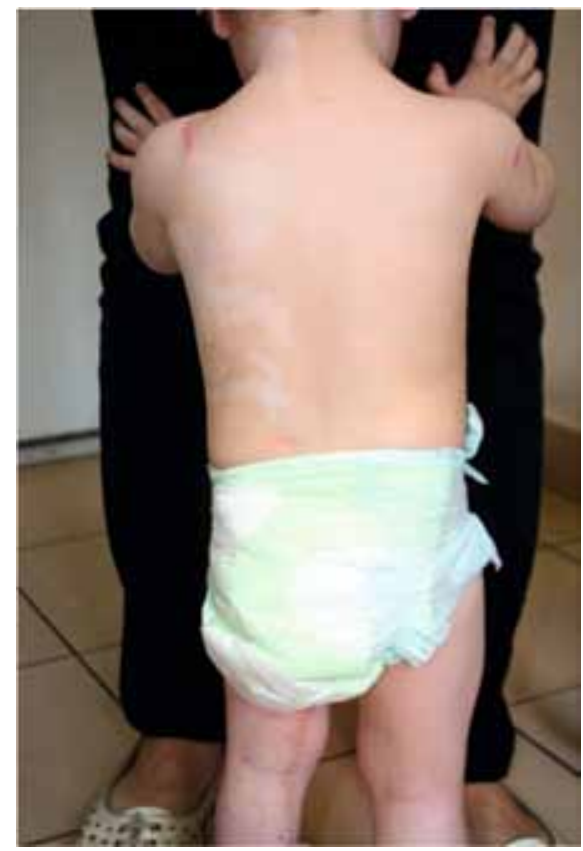

Рипопигментированные V-образные или фонтаноподобные пятна по типу узких линий Блашко 


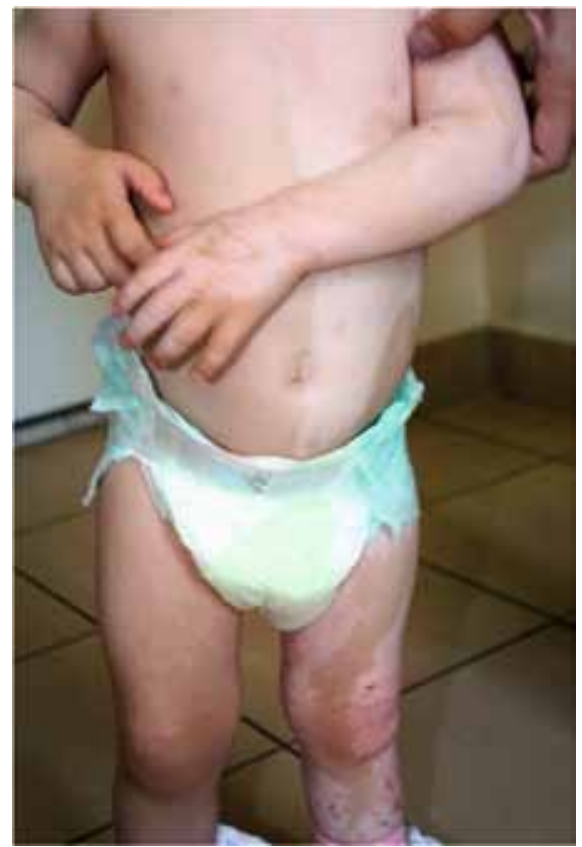

Рис. 4. Линейные очаги депигментации с островками нормально пигментированной кожи

Диагноз и дифференциальный диагноз. Наличие на коже ребенка в раннем возрасте очагов гипопигментации не позволяет исключить генетически обусловленную дисхромию, в первую очередь наследственное витилиго или пьебалдизм. Заболевание характеризуется врожденными симметричными депигментированными пятнами на коже лба, центральной части груди, живота, верхних третей конечностей. В пределах очагов на конечностях сохраняются островки нормальной пигментации, что мы наблюдаем в нашем клиническом примере. В то же время одним из ключевых симптомов этого заболевания считается характерная треугольная депигментация на лбу в сочетании с белыми волосами во фронтальной области волосистой части головы. Указанные клинические особенности отмечены у 80-90\% больных пьебалдизмом [4]. В обсуждаемом нами случае очаги депигментации на лице не типичны для наследственного витилиго, характерного обесцвечивания волос нет. Кроме того, все очаги имеют четкое асимметричное расположение преимущественно слева. Гипопигментация распространяется и на область кисти, в то время как при пьебалдизме кисти и стопы нормально пигментированы. Предполагаемый у ребенка диагноз синдрома Ваарденбурга (Waardenburg) также не правомочен, поскольку характеризуется помимо депигментированных пятен на туловище телекантом (латеральное смещение внутреннего угла глаз), гетерохромией радужки, седой прядью на лбу и врожденной глухотой. Относительно диагноза синдрома Блоха Сульцбергера следует отметить, что, действительно, характерные S- и V-образные очертания очагов у ребенка укладываются в клиническую картину синдрома Блоха - Сульцбергера или недержания пигмента, но при указанном синдроме высыпания характеризуются не гипопигментированными, а гиперпигментированными пятнами по типу «брызг грязи».

Таким образом, у ребенка имеет место врожденное нарушение пигментации с асимметричным расположением очагов определенной конфигурации, сопутствующая патология нервной, зрительной и костной систем. Все перечисленное характерно для такой генетически обусловленной патологии, как невоидная гипопигментация (невоидный гипомеланоз).

Поскольку заболевание имеет генетическую природу, тактики лечения не разработано. Рекомендации включают в себя ограничение инсоляции, использование фотозащитных средств, диспансерное наблюдение невропатологом и ортопедом.

\section{Обсуждение}

Так называемые линии Блашко, или линии, отражающие миграцию клеток нервного гребня в эмбриогенезе, были открыты немецким ученым Альфредом Блашко в 1901 г. при описании дерматозов с завитковым, волнистым и линейным расположением очагов [5]. Подобное расположение в первую очередь характерно для высыпаний по типу «брызг грязи» при синдроме Блоха - Сульцбергера, или недержания пигмента. Позже в 1952 г. японским дерматологом Ито было приведено описание наблюдения 21-летней пациентки с аналогичными гипопигментированными волнистыми и завиткообразными пятнами. Автор назвал это состояние «недержание пигмента ахромическое». Впоследствии во избежание путаницы был введен термин «гипомеланоз Ито». Пациенты с гипомеланозом Ито могут иметь нарушения нервной и костной систем, органа зрения [6, 7]. В настоящее время вместо «гипомеланоз Ито» чаще употребляются термины «невоидная гипопигментация» или «мозаичная гипопигментация». Состояние это характеризуется уни- или билатерально расположенными очагами гипопигментации вдоль линий Блашко как в сочетании с различными системными аномалиями, так и без них [8]. 


\section{Литература}

1. Alper J.C., Holmes L.B. The incidence and significance of birthmarks in a cohort of 4641 newborns. Pediatr Dermatol. 1983; 1: 58-68.

2. Happle R. Mosaicism in human skin: understanding the patterns and mechanisms. Arch Dermatol 129-1460.

3. Happle. R. Pigmentary patterns associated with human mosaicism: a proposed classification. Eur J Dermatol 1993; 3: 170.
4. Thomas I., Kihiczak G.G., Fox M.D. et al. Piebaldism: an update. Int J Dermatol 2004; 43: 716-719.

5. Happle R., Assim A. The lines of Blashko on the head and neck. J Am Acad Dermatol 2001; 44: 612.

6. Rutland B.M., Edgar M.A., Horenstien M.G. Hypomelanosis of Ito associated with precocious puberty. Pediatr Neurol 2006; 34: 51—54.
7. Tragardh M., Thomsen C.R., Thorninger R., Moller-Madsen B. Hypomelanosis of Ito presenting with pediatric orthopedic issues: a case report. J Med Case Rep. 2014 May 19; 8: 156. doi: 10.1186/1752-1947-8-156.

8. Cohen J., Shahrokh K., Cohen B. Analysis of 36 cases of Blaschkoid dyspigmentation: reading between the lines of Blaschko. Pediatr Dermatol. 2014 Jul-Aug; 31 (4): 471-6 doi:10.1111/pde.12346.

об авторах:

Д.В. Прошутинская - д.м.н., ведущий научный сотрудник отделения детской дерматологии ФГБУ «ГНЦДК» Минздрава России, Москва

Л.В. Текучева — К.м.Н., старший научный сотрудник отделения детской дерматологии ФГБУ «ГНЦДК» Минздрава России, Москва

\section{Конфликт интересов}

Авторы заявляют об отсутствии потенциального конфликта интересов, требующего раскрытия в данной статье 